\title{
Hydrostatic Compress Force Enhances the Viability and Decreases the Apoptosis of Condylar Chondrocytes through Integrin-FAK-ERK/PI3K Pathway
}

\author{
Dandan Ma ${ }^{1,2}$, Xiaoxing Kou ${ }^{3}$, Jing Jin ${ }^{1}$, Taotao $\mathrm{Xu}^{4}{ }^{4}$, Mengjie $\mathrm{Wu}^{5}$, Liquan Deng ${ }^{1}$, Lusi Fu ${ }^{1}$, \\ Yi Liu ${ }^{2}$, Gang $\mathrm{Wu}^{2, *}$ and Haiping $\mathrm{Lu}^{1, *}$ \\ 1 School of Stomatology, Zhejiang Chinese Medical University, Hangzhou 310053, China; \\ whiterose1989@126.com (D.M.); jinjingtoday@163.com (J.J.); totti.12345@163.com (L.D.); fulusi@126.com (L.F.) \\ 2 Department of Oral Implantology and Prosthetic Dentistry, Academic Centre for Dentistry \\ Amsterdam (ACTA), VU University Amsterdam and University of Amsterdam, MOVE Research Institute, \\ Gustav Mahlerlaan 3004, Amsterdam 1081LA, Nord-Holland, The Netherlands; liuzzd@163.com \\ 3 Department of Orthodontics, Peking University School and Hospital of Stomatology, Beijing 100081, China; \\ kouxiaoxing@gmail.com \\ 4 Department of Orthopaedic Surgery, the First Affiliated Hospital of Zhejiang Chinese Medical University, \\ Hangzhou 310006, China; nacle1990829@163.com \\ 5 Department of Orthodontics, Stomatology Hospital Affiliated to Zhejiang University, Hangzhou 310053, \\ China; baobalala@sina.cn \\ * Correspondence: g.wu@acta.nl (G.W.); haipinglushu@hotmail.com (H.L.); Tel.: +31-20-598-0866 (G.W.); \\ +86-571-8663-3080 (H.L.); Fax: +31-20-598-0333 (G.W.); +86-571-8663-3080 (H.L.)
}

Academic Editor: Ali Mobasheri

Received: 29 July 2016; Accepted: 31 October 2016; Published: 7 November 2016

\begin{abstract}
Reduced mechanical stimuli in many pathological cases, such as hemimastication and limited masticatory movements, can significantly affect the metabolic activity of mandibular condylar chondrocytes and the growth of mandibles. However, the molecular mechanisms for these phenomena remain unclear. In this study, we hypothesized that integrin-focal adhesion kinase (FAK)-ERK (extracellular signal-regulated kinase)/PI3K (phosphatidylinositol-3-kinase) signaling pathway mediated the cellular response of condylar chondrocytes to mechanical loading. Primary condylar chondrocytes were exposed to hydrostatic compressive forces (HCFs) of different magnitudes $(0,50,100,150,200$, and $250 \mathrm{kPa})$ for $2 \mathrm{~h}$. We measured the viability, morphology, and apoptosis of the chondrocytes with different treatments as well as the gene, protein expression, and phosphorylation of mechanosensitivity-related molecules, such as integrin $\alpha 2$, integrin $\alpha 5$, integrin $\beta 1$, FAK, ERK, and PI3K. HCFs could significantly increase the viability and surface area of condylar chondrocytes and decrease their apoptosis in a dose-dependent manner. HCF of $250 \mathrm{kPa}$ resulted in a $1.51 \pm 0.02$-fold increase of cell viability and reduced the ratio of apoptotic cells from $18.10 \% \pm 0.56 \%$ to $7.30 \% \pm 1.43 \%$. HCFs could significantly enhance the mRNA and protein expression of integrin $\alpha 2$, integrin $\alpha 5$, and integrin $\beta 1$ in a dose-dependent manner, but not ERK1, ERK2, or PI3K. Instead, HCF could significantly increase phosphorylation levels of FAK, ERK1/2, and PI3K in a dose-dependent manner. Cilengitide, the potent integrin inhibitor, could dose-dependently block such effects of HCFs. HCFs enhances the viability and decreases the apoptosis of condylar chondrocytes through the integrin-FAK-ERK/PI3K pathway.
\end{abstract}

Keywords: integrin; FAK; ERK; PI3K; mandibular condyle; chondrocyte; apoptosis

\section{Introduction}

The temporomandibular joint (TMJ) is an important contributor to the growth of the mandible length and height. Mandibular condylar cartilage in the temporomandibular joint is the greatest 
growth center in the craniofacial complex. The proper proliferation, maturation, and endochondral ossification of mandibular condylar cartilages are of paramount importance for the maxillofacial skeleton morphogenesis and temporomandibular joint functions [1].

Sufficient mechanical stimulus during the mandible movement plays a critical role in maintaining the survival, proper growth, and functions of mandibular condylar cartilage. Reduced mechanical stimuli in many pathological cases-such as soft diet, hemimastication, and limited masticatory movements-can significantly affect the metabolic activity of mandibular condylar cartilages and the growth of mandible. In clinical cases, such compromised mechanical stimuli could lead to significantly less growth activity of the condylar cartilage and macroscopic growth of the lower jaw [2-4]. In simulated animal models, reduced masticatory forces could result in a lower number of chondrocytes and cell layers, thinner condylar cartilages, and a reduction in trabecular bone density deep to the cartilage [5-8]. The cellular mechanisms accounting for these pathological changes may be the marked reduction in metabolic activities, such as proliferative activity and proteoglycan synthesis in mandibular condylar cartilage [9]. Besides, the inhibited growth of the developing mandible was also found to be related to the increased apoptosis and death of chondrocytes at the proliferation stage of the reserve zone $[10,11]$. These results indicated that sufficient loading was important for preventing apoptosis and maintaining the metabolic activities of condylar chondrocytes [9]. However, the molecular signaling transduction pathway accounting for the effects of extracellular mechanical forces on intracellular metabolic activities of mandibular condylar chondrocytes remains largely unveiled.

Integrins, a group of heterodimeric cell-surface molecules, are one of the most important mediators for the extracellular-intracellular signaling transduction. Each integrin molecule consists of two different chains: $\alpha$ and $\beta$ subunits. In mammals, there are $18 \alpha$ and $8 \beta$ subunits [12]. Integrin $\alpha 5 \beta 1$, the classic receptor for fibronectin, seems to be very important for the transmission of mechanical forces from extracellular matrix to cells [13,14]. Following the activation of integrins, focal adhesion kinase (FAK), as one of the main integrin-associated signaling and adaptor molecules, will be phosphorylated to mediate the intracellular effect of mechanical forces [15-17]. The involvement of integrin $\alpha 5 \beta 1$-FAK signaling pathways in mediating the biological response to mechanical stimuli was further corroborated by the in vivo finding that an elevated mechanical stimulus resulted in a significantly higher level of the integrin $\alpha 5 \beta 1$ and FAK than the sides with a reduced mechanical stimulus [18]. In addition, integrin $\alpha 2$ was shown to be also associated with the survival of condylar cartilage [19]. FAK can further cooperatively interact with receptor tyrosine kinase signaling to regulate adhesion, migration, survival, proliferation, polarization, and differentiation [20]. For example, FAK acted as an upstream regulator of the ERK1/2 (extracellular signal-regulated kinase) signaling upon mechanical stimulation in many cell types [21,22]. Following activation, phosphorylated ERK1/2 could translocate to the nucleus and activate transcription factors that are involved in response to mechanical stimulation [23]. FAK could also modulate cell apoptosis by involving PI3K (phosphatidylinositol-3-kinase) pathways [24].

Hitherto, it remains unclear whether integrin-FAK-ERK/PI3K signaling pathways mediate the cellular response of condylar chondrocytes to mechanical loading. In this study, we adopted an apparatus for administrating hydrostatic compressive forces (HCFs) to mimic the mechanical microenvironment of the masticatory forces. Thereby, we wished to approach the mechanotransduction mechanisms of primary condylar chondrocytes by assessing their proliferation, apoptosis, and signaling pathways under the stimulation of different-magnitude HCFs.

\section{Results}

\subsection{Characterization of Primary Condylar Chondrocytes}

The primary chondrocytes showed a polygonal morphology. They displayed positive toluidine blue staining for glycosaminoglycans (Figure 1A). The primary chondrocytes were also positive for type II collagen (Figure 1B) and aggrecan staining (Figure 1C). Meanwhile, they were negative for 
type-I (Figure 1D) and type-X collagen staining (Figure 1E). These results demonstrated that the primary condylar chondrocytes were suitable for later experiment.
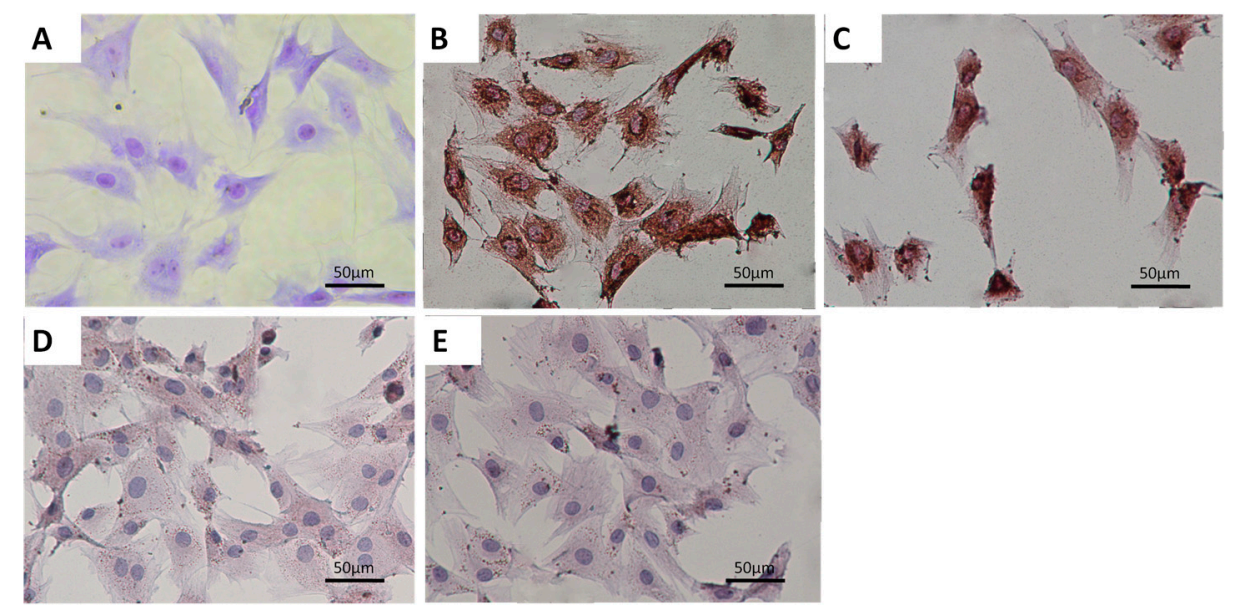

Figure 1. The primary mandibular condylar chondrocytes of rats were characterized using both (A) toluidine blue staining and (B-E) immunocytochemistry staining. These cells were positive for (B) type-II collagen and (C) aggrecan staining. They were also negative for (D) type I collagen and (E) type $X$ collagen staining. Scale bar $=50 \mu \mathrm{m}$.

\subsection{HCFs Could Promote the Proliferation and Decrease the Apoptosis of Condylar Chondrocytes}

When no HCFs were applied, the primary condylar chondrocytes showed a high apoptotic ratio of about $19.10 \% \pm 0.70 \%$ (Figure $2 \mathrm{~B}$ ). HCFs of $50-250 \mathrm{kPa}$ could significantly enhance the cell viability (Figure 2A) and decreased the apoptosis (Figure 2B) of condylar chondrocytes in a dose-dependent manner. HCF of $250 \mathrm{kPa}$ resulted in a $1.51 \pm 0.02$-fold increase of cell viability and reduced the ratio of apoptotic cells from $18.10 \% \pm 0.56 \%$ to $7.30 \% \pm 1.43 \%$. Flowcytometric analysis showed that $250 \mathrm{kPa}$ resulted in the reduction of early apoptotic, late apoptotic, and necrotic cells by $35.36 \%, 61.0 \%$, and $46.4 \%$, respectively (Figure 3). Cilengitide, the potent integrin inhibitor, could dose-dependently block such effects of HCFs (Figures 2 and 3).
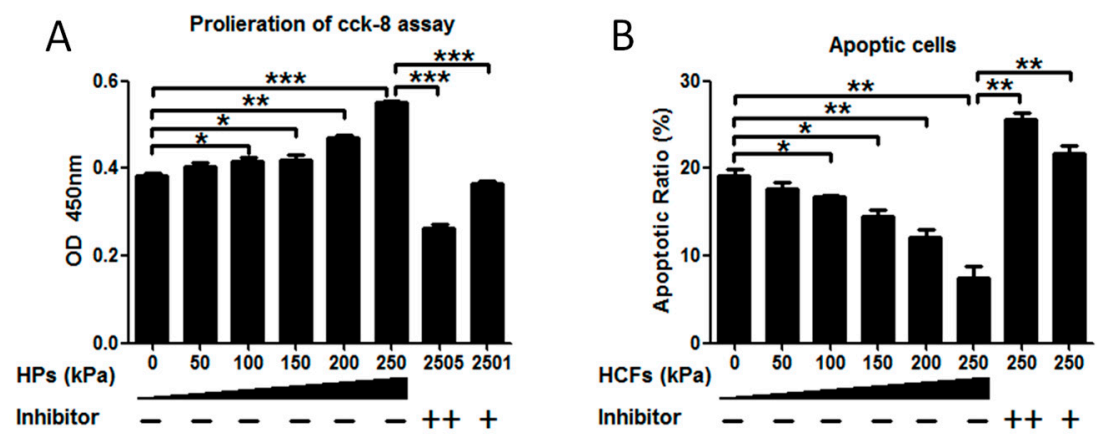

Figure 2. Hydrostatic compressive forces (HCFs) of different magnitudes $(0-250 \mathrm{kPa})$ for $2 \mathrm{~h}$ significantly (A) enhanced the viability and (B) decreased the apoptosis of primary rat mandibular condylar chondrocytes in a dose-dependent manner. Such effects could completely inhibited by the integrin inhibitor-cilengitide of 1 or $5 \mu \mathrm{g} / \mathrm{mL}$. All the data were presented as mean \pm standard deviation (SD). $n=5$ per group. ${ }^{*} p<0.05 ;{ }^{* *} p<0.01 ;{ }^{* * *} p<0.001$. 


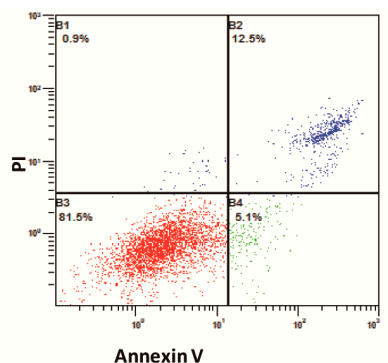

OkPa

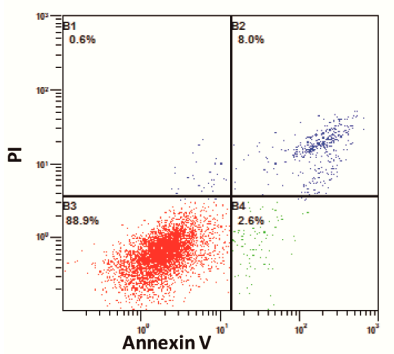

$200 \mathrm{kPa}$

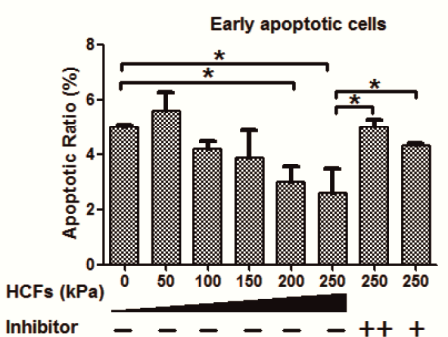

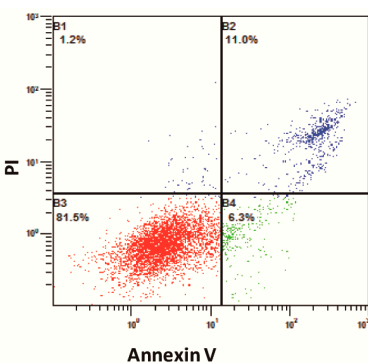

$50 \mathrm{kPa}$

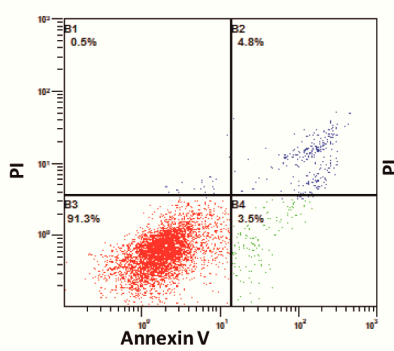

$250 \mathrm{kPa}$

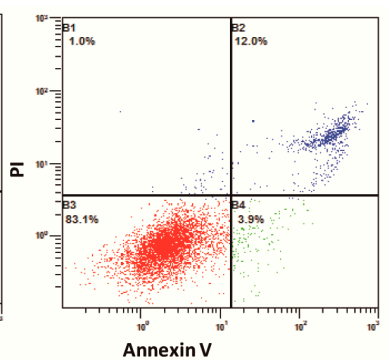

$100 \mathrm{kPa}$

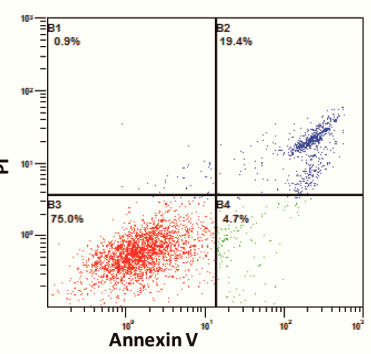

$250 \mathrm{kPa}+5 \mu \mathrm{g} / \mathrm{ml}$ cilengitide

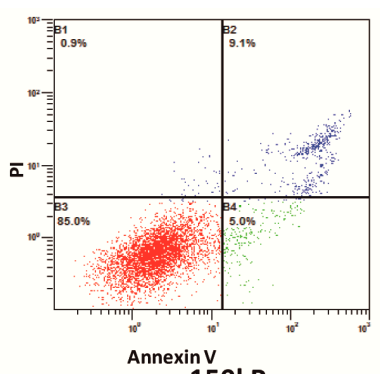

$150 \mathrm{kPa}$

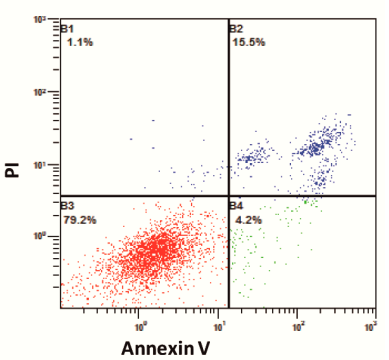

$250 \mathrm{kPa}+1 \mu \mathrm{g} / \mathrm{ml}$ cilengitide
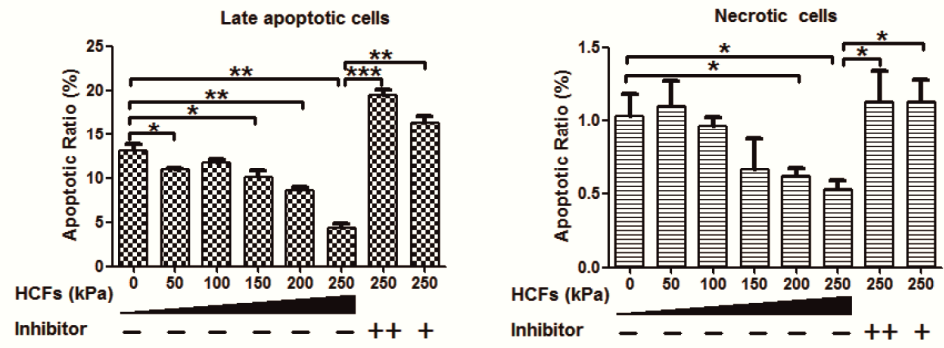

Figure 3. Flow cytometric analysis to detect the rates of apoptotic mandibular condylar chondrocytes under the treatment of hydrostatic compressive forces (HCFs) of different magnitudes $(0-250 \mathrm{kPa})$ without or with 1 or $5 \mu \mathrm{g} / \mathrm{mL}$ Cilengitide. Cells were stained with FITC (Fluorescein isothiocyanate)-Annexin $\mathrm{V}$ and propidium iodide (PI). Viable cells were in the bottom left quadrant (red), early apoptotic cells were in the bottom right quadrant (green), the late apoptotic cells were in the upper right quadrant (blue) and the necrotic cells were in the upper left quadrant (blue). Graphs depicting the effects of HCFs on the rates of the early apoptotic, late apoptotic, and necrotic mandibular condylar chondrocytes. ${ }^{*} p<0.05 ;{ }^{* *} p<0.01 ; * * * 0.001$.

\subsection{HCFs Enlarged the Surface Area of Condylar Chondrocytes without Changing Their Chondrocyte Phenotype}

Typical morphology alternations of condylar chondrocytes under HCFs were shown in the Figure 4. Without $\mathrm{HCF}$, the condylar chondrocytes were predominantly small and polygonal (Figure 4A). In contrast, HCF of $250 \mathrm{kPa}$ enhanced the cell spreading and resulted in a 1.57-fold surface area of the control group (Figure $4 \mathrm{~B}, \mathrm{E}$ ). Such an effect of HCF was completely inhibited when treating the cells with 5 and $1 \mu \mathrm{g} / \mathrm{mL}$ cilengitide. After the treatment of HCFs, the condylar chondrocytes remained positive for type-II collagen (Figure 5A,E)and aggrecan (Figure 5B,F) staining, and negative for type-I collagen (Figure 5C,G) and type-X collagen (Figure 5D,H) 

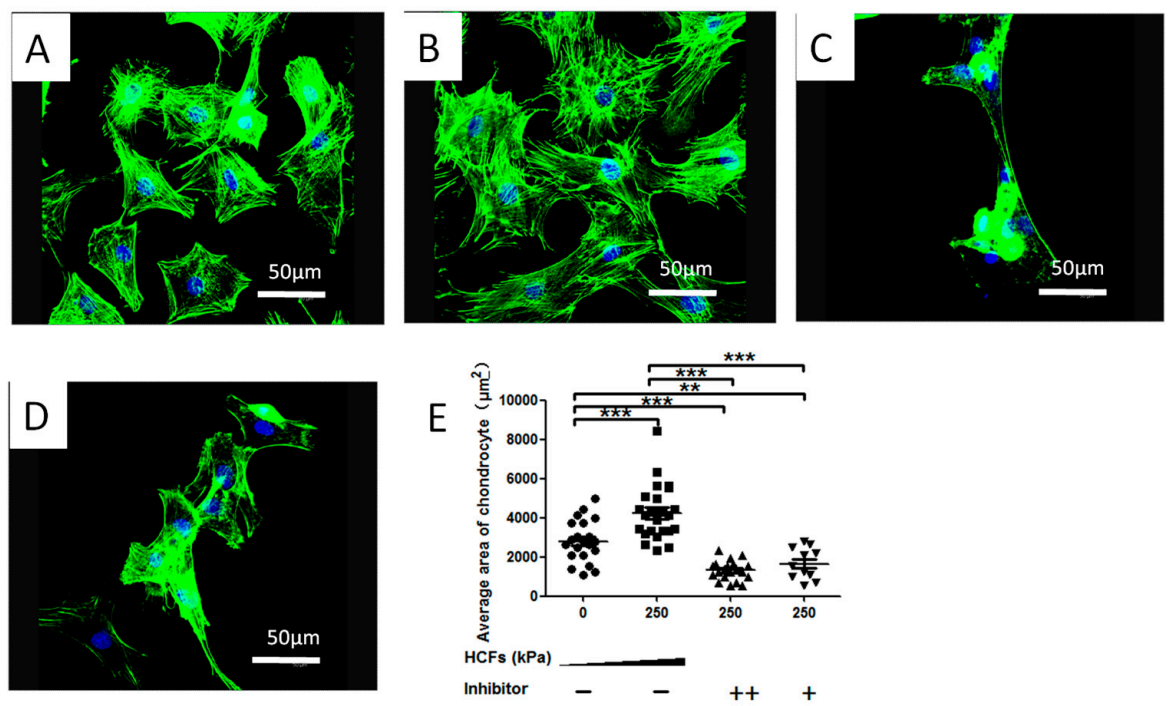

Figure 4. Immunofluorescent micrographs depicting the F-actin distribution in mandibular condylar chondrocytes with (A) no HCF treatment $(0 \mathrm{kPa})$; (B) the treatment of $250 \mathrm{kPa} \mathrm{HCF}$; (C) the treatment of $250 \mathrm{kPa} \mathrm{HCF}$ plus $1 \mu \mathrm{g} / \mathrm{mL}$ cilengitide; and (D) the treatment of $250 \mathrm{kPa} \mathrm{HCF}$ plus $5 \mu \mathrm{g} / \mathrm{mL}$ cilengitide; (E) graph depicting the surface area of cells under the abovementioned treatments. All data are presented as mean \pm standard deviation (SD). ${ }^{* *} p<0.01 ;{ }^{* * *} p<0.001$.

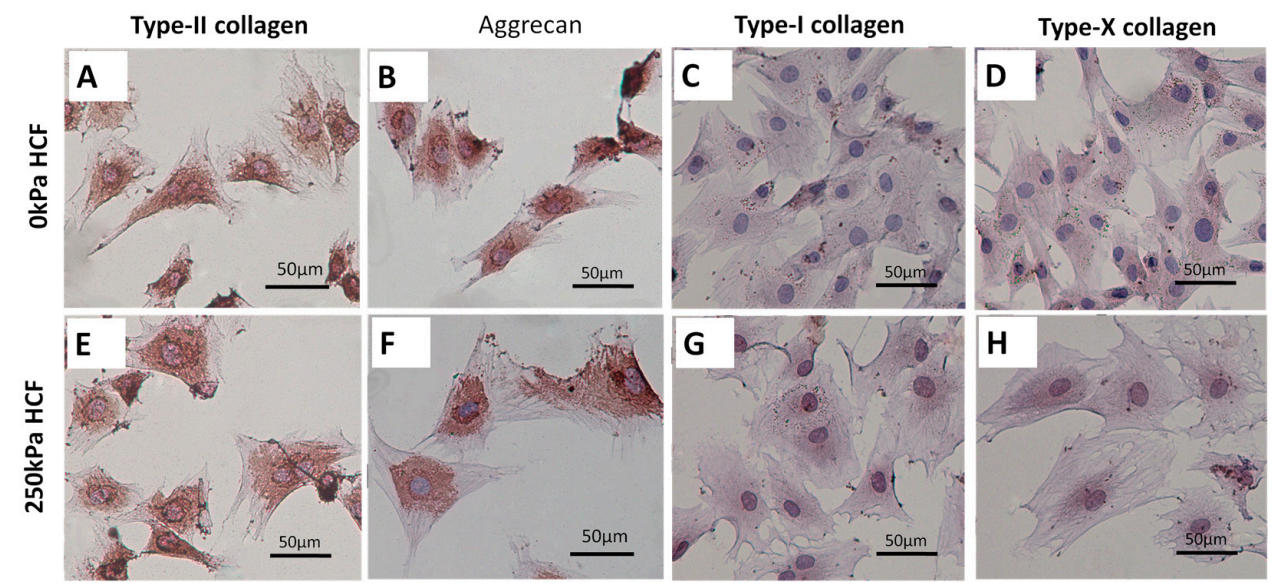

Figure 5. Light micrographs depicting the primary mandibular condylar chondrocytes that were treated with either $0(\mathbf{A}-\mathbf{D})$ or $250 \mathrm{kPa} \mathrm{HCF}$ treatment $(\mathbf{E}-\mathbf{H})$. Thereafter, these primary cells were subjected to immunocytochemistry staining for type-II collagen (A,E); aggrecan (B,F); type-I collagen $(\mathbf{C}, \mathbf{G})$; and type-X collagen $(\mathbf{D}, \mathbf{H})$. Scale bar $=50 \mu \mathrm{m}$.

\subsection{Change of Integrin $\alpha 2$, Integrin $\alpha 5$, Integrin $\beta 1, F A K, E R K 1 / 2$, and PI3K under Various HCFs}

HCFs could significantly enhance the mRNA expression of integrin $\alpha 2$, integrin $\alpha 5$, integrin $\beta 1$, and FAK in a dose-dependent manner, but not ERK1, ERK2, or PI3K. HCF of $250 \mathrm{kPa}$ could result in 4.8-, 3.6-, 5.8-, and 6.1-fold increases of integrin $\alpha 2$, integrin $\alpha 5$, integrin $\beta 1$, and FAK mRNA expressions than the control (without HCFs), respectively (Figure 6). Consistently, HCF also dose-dependently increased the protein expression of integrin $\alpha 2$, integrin $\alpha 5$, and integrin $\beta 1$ but not FAK, ERK1/2, or PI3K. Instead, HCF could significantly increase phosphorylation levels of FAK, ERK1/2, and PI3K in a dose-dependent manner (Figure 7). On the other hand, HCF could also dose-dependently decrease the protein expression of caspase-3 (Figure 7). This HCFs-induced enhancement in the mRNA, protein expression, and phosphorylation levels of the key molecules could be completely inhibited by the potent integrin inhibitor, cilengitide. 

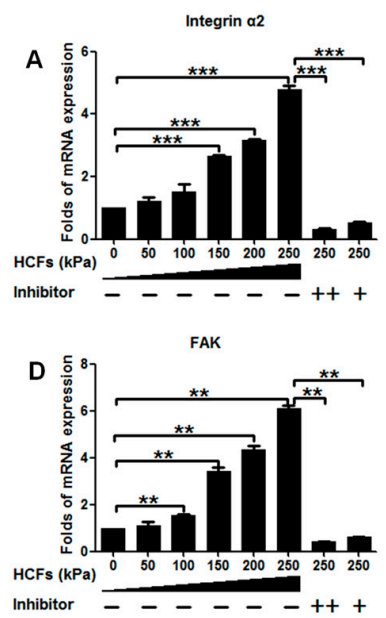

PIK3

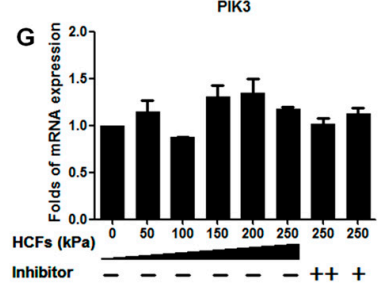

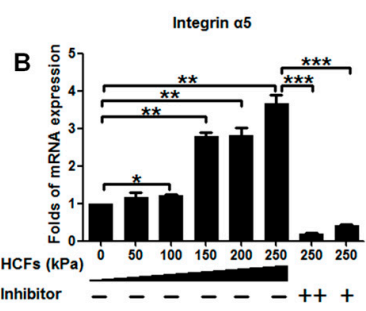

ERK1

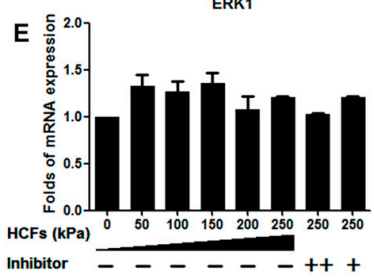

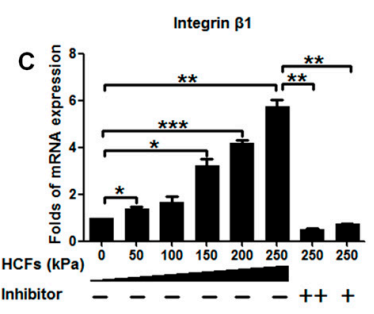

ERK2

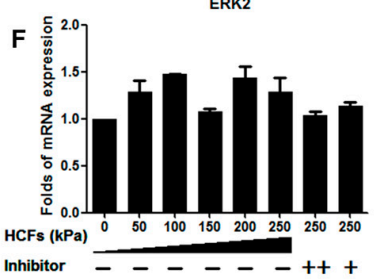

Figure 6. Quantitative real-time PCR analysis to detect depicting the mRNA expression levels of (A) integrin $\alpha 2$; (B) integrin $\alpha 5$; (C) integrin $\beta 1$; (D) FAK; (E) ERK1; (F) ERK2; and (G) PI3K in mandibular condylar chondrocytes with the treatments of hydrostatic compressive forces of different magnitudes $(0-250 \mathrm{kPa})$ in the presence or absence of $5 \mathrm{or} 1 \mu \mathrm{g} / \mathrm{mL}$ cilengitide. All data are presented as mean \pm standard deviation (SD). $n=5$ per group. ${ }^{*} p<0.05 ;{ }^{* *} p<0.01 ;{ }^{* * *} p<0.001$.
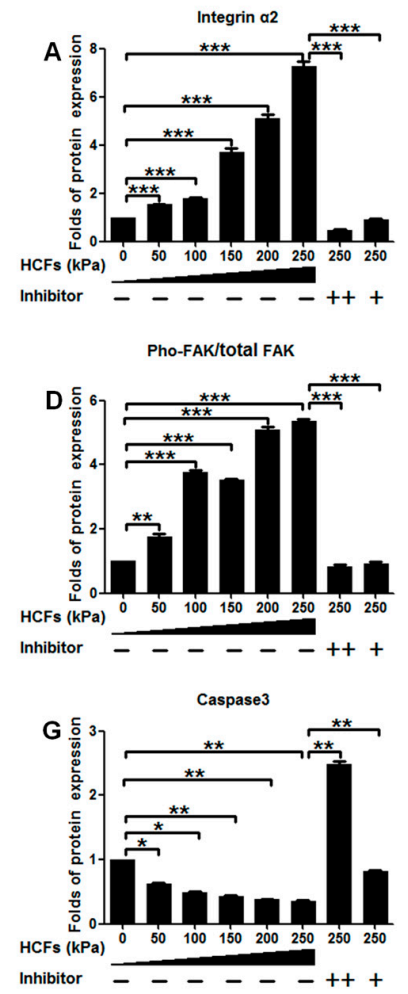
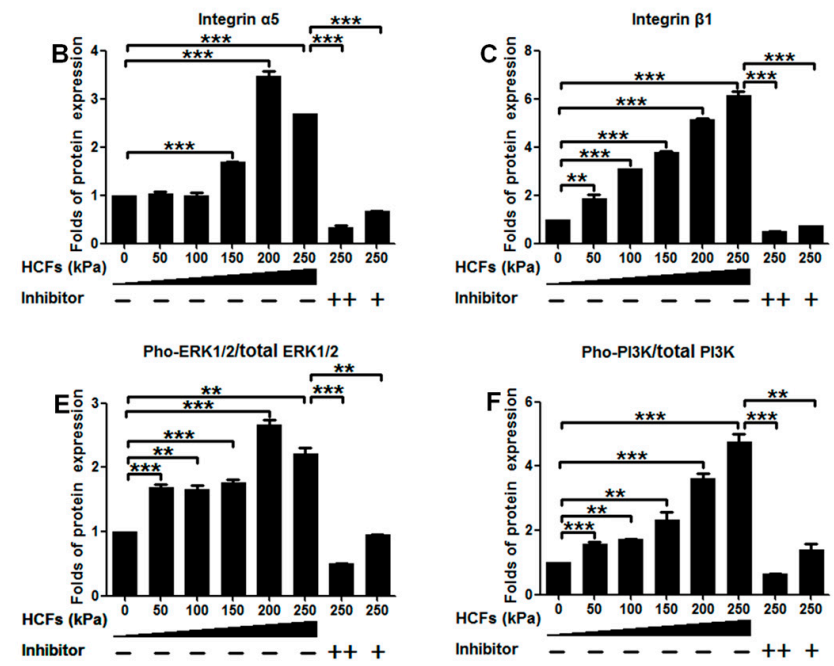

Figure 7. Cont. 


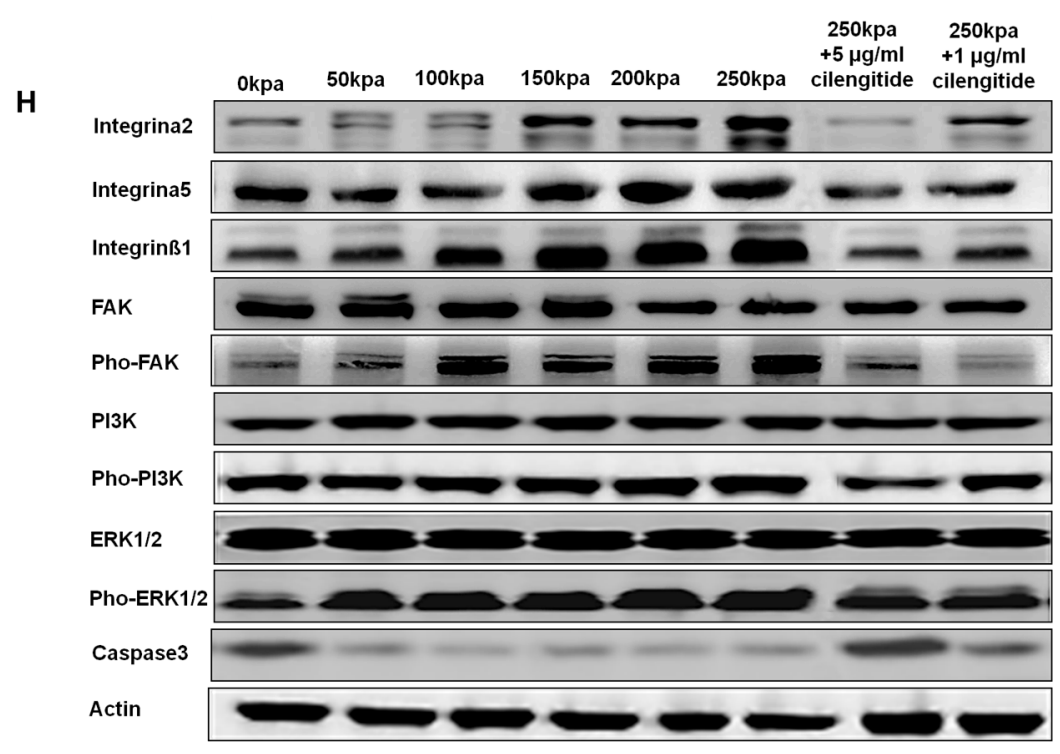

Figure 7. Western blotting analyses to detect the protein expression of (A) integrin $\alpha 2 ;(\mathbf{B})$ integrin $\alpha 5 ;$ (C) integrin $\beta 1 ;$ (D) Pho-FAK/FAK; (E) Pho-ERK/ERK, (F) Pho-PI3K/PI3K; and (G) Caspase 3 in mandibular condylar chondrocytes with the treatments of hydrostatic compressive forces of different magnitudes $(0-250 \mathrm{kPa})$ in the presence or absence of 5 or $1 \mu \mathrm{g} / \mathrm{mL}$ cilengitide $(\mathbf{H})$. All data are presented as mean \pm standard deviation (SD). $n=5$ per group. $n=5$ per group. ${ }^{*} p<0.05 ;{ }^{* *} p<0.01$; *** $p<0.001$.

\section{Discussion}

The basic functions of the TMJ is to enable the movements of mandible for many oral functions, such as speaking, chewing, and swallowing. During these movements, mechanical forces are transmitted to condylar cartilage, which conversely play an important role in promoting the growth of condylar cartilage. A compromised mechanical stimulus caused by limited or altered masticatory functions will lead to both a decrease in growth an increase in atrophy of condylar cartilage. However, the molecular mechanisms mediating the effects of mechanical stimuli on the metabolic activities of condylar chondrocytes remain unclear. In this study, we showed that the integrin-FAK-ERK/PI3K mediated the important roles of mechanical stimuli in promoting the proliferation activities and reducing the apoptosis of primary condylar chondrocytes.

It is nearly impossible to measure the real magnitude of mechanical loadings on condylar cartilages during masticatory movements. To approach this problem, finite element models were established on the basis of magnetic resonance images from two subjects with or without anterior disc displacement of the TMJ $[25,26]$. The stress values after a 10-min clenching varied from 20 to $100 \mathrm{kPa}$ according to the different sites of condylar cartilage [25,26]. It was also shown that rabbit chondrocytes subjected to stress ranging from 0 to $200 \mathrm{kPa}$ yielded tissue-engineered cartilage of the best quality [27]. On the other hand, an unphysiologically high loading would significantly enhance the death of cartilage $[28,29]$. Consequently, to mimic the real mechanical stimuli and keep the comparability with previous studies, we adopted the HCFs ranging from 0 to $250 \mathrm{kPa}$ in the present study. On the other hand, various types of apparatuses were used to investigate the effects of HCFs on chondrocytes. The thereby generated HCFs could be cyclic [30] or continuous (as in our study) or sinusoidal [31]. The magnitudes of HCFs could vary from from $\mathrm{kPa}$ to MPa and the duration also varied from hours to days. The in vitro metabolic activities of chondrocytes to HCFs varied with the magnitude, frequency, and duration of loading. Pathological microenvironments could also be created by adding pro-inflammatory cytokines to investigate the effects of HCFs on the metabolic activities of chondrocytes in osteoarhritis [32]. In addition, caution should also be taken to extrapolate the current findings to the articular cartilage-derived chondrocytes due to the 
unique phenotype of condylar chondrocytes [33]. As secondary cartilages (local mesenchymal cartilage formation), mandibular condylar cartilages, are fibrocartilages that are structurally distinct from both the limb growth plate and the articular cartilage. It differs from primary cartilage in patterns of the endochondral ossification, cellular organization, in vivo transplant growth, and antigenicity [34]. Under HCFs, mandibular condylar chondrocytes reacted differentially both in time-dependent profile and magnitudes in comparison with primary cartilage-derived chondrocytes [34].

When the primary condylar chondrocytes were isolated and cultured on cover slides in vitro, they showed a very high rate (11\%-30\%) of apoptosis [35]. Consistent with this result, the primary condylar chondrocytes cultured on cover slides exhibited an apoptotic ratio of $18.10 \% \pm 0.56 \%$ (Figure 3 ). Such apoptosis might be due to the lack of stimulating signals for maintaining the survival of primary chondrocytes in this unphysiological and suboptimal microenvironment [35]. It was previously shown that cell-matrix interactions via integrins were necessary for all chondrocytes to survive [19,35]. The metabolic activity of primary chondrocytes was also associated with mechanical signals, whose effects were also mediated by integrins [27]. Furthermore, we also showed that HCF could not only significantly enhance the viability (Figure 2A) but also decrease apoptosis of primary chondrocytes in a dose-dependent manner (Figure 2B). Consistently, we also showed that expression of caspase-3 could be significantly reduced by HCFs (Figure 7G). Furthermore, our data showed that HCF could significantly and dose-dependently promote the expression of integrin $\beta 1$, integrin $\alpha 2$, and integrin $\alpha 5$ both in transcriptional levels (mRNA expression) and translational levels (protein expression) in the primary condylar chondrocytes (Figures 6 and 7). Such effects could be completely inhibited by the competitive inhibitor of integrins (Figures 6 and 7). In fact, integrins, such as integrin $\beta 1$ and integrin $\alpha 5$ are the major mediators of mechanical signals in chondrocytes [36] but also in many other cell types, such as in myocardial cells [37] and fibroblasts [38]. Consequently, integrins are very likely to be the converging molecular harbor for sensing the signals from cell matrix and mechanical forces, thereby playing an important role in modulating the viability and apoptosis of condylar chondrocytes.

FAK, a cytoplasmic tyrosine kinase located in the focal adhesion complex, has been implicated in the signal transduction from integrins $[39,40]$. FAK played an anti-apoptotic role $[24,41,42]$ FAK acted as an upstream regulator of the ERK1/2 signaling upon mechanical stimulation in many non-chondrocytic cell types $[21,22]$. The downregulation of FAK could significantly reduce ERK and Akt survival signaling, subsequently leading to apoptosis [43]. This association of FAK-Src, together with the Grb2 adaptor protein, represents one mechanism for the activation of ERK by FAK [44]. The pho-ERK1/2 could migrate from the cytosol to the nucleus where they regulate the activity of transcription factors [45]. The importance of pho-ERK $1 / 2$ to chondrocyte survival was corroborated by the fact the specific inhibition of ERK1/2 activation could result in apoptosis of human chondrocytes [46]. FAK could also directly activate PI3K [47,48]. Consistent with those previous reports, our data showed that Pho-ERK1/2 and Pho-PI3K were significantly promoted in a dose-dependent manner in response to HCFs (Figure 7). Furthermore, the inhibition of integrins could completely inhibit the elevation of Pho-ERK1/2 and Pho-PI3K. These data indicated that ERK and PI3K were actively involved in the mechanical forces-induced integrin signaling transduction.

Hitherto, it remains not clarified how mechanical forces modulate caspase in chondrocytes. Previous studies suggested that the inhibited integrin-ligand interactions by Arg-Gly-Asp peptides could cause apoptosis through the conformational changes in the uncleaved caspase- 3 molecule, leading to its auto-cleavage and generation of active caspase- 3 molecules in anchorage-dependent cells [49]. Consequently, for the isolated primary chondrocytes, the reduced interactions of integration with cellular matrix might cause the increased expression of caspase-3, thus resulting in a very high apoptotic rate (Figure 2B). Consistent with this principle, the activation of integrin was rescued by HCFs in our study (Figures 6 and 7), which could directly reduce caspase-3 (Figure 7G) and apoptosis (Figures 2 and 3). On the other hand, FAK could also regulate the activity of caspase by facilitating the marked induction of inhibitor-of-apoptosis proteins, by a proposed mechanism involving PI3K/Akt 
activation of the NF- $\mathrm{kB}$ pathway [24]. Further studies must be performed to identify the mechanism accounting for the modulation of caspase by mechanical forces in chondrocytes.

HCFs could significantly enhance the surface area of the primary condylar chondrocytes. HCF of $250 \mathrm{kPa}$ resulted in a 1.57-fold surface area of the control group (Figure 4). Meanwhile, the cell viability and proliferation index of the chondrocytes were significantly enhanced (Figure 2). It was previously suggested that this shape change has been associated with a number of biochemical changes. In mammalian cells, a high correlation has been reported between cellular shape and proliferation [50-52]. A greater mitotic activity was observed among the flattest cells. In contrast, minimal DNA synthesis was found among the roundest cells. In addition, we found that the condylar chondrocytes remained positive for aggrecan and type-II collagen staining, and negative for type-I and type-X collagen staining (Figure 5). These findings suggested that the HCFs affected the metabolic activities of the condylar chondrocytes without significantly changing their chondrocytic phenotype. Indeed, flat polygonal vertebral chondrocytes in culture showed a progressive increase in size and type-X collagen gene expression as a function of time in culture [53]. Similar changes were found during the maturation processes of epiphyseal cartilages [54]. Our experiments confirmed these observations, since the greatest increase in cell number occurred under various magnitude of HCF in culture, just after the cells had extensively spread out. Meanwhile, a marked decrease in cell viability occurred to the cells that shrank when treated with the integrin inhibitor, cilengitide. The results suggested that integrins also mediated the HCFs-induced morphological changes.

One of the limitations in this study is the adoption of a monolayer culture system instead of a 3D culture system. A 3D culture system may more simulate the real microenvironments of condylar chondrocytes, such as three-dimensional anchorage and signals from cell matrix [55-57], which may significantly affect the mechanosensitivity of condylar chondrocytes. In our future study, we will develop a 3D culture system and access the cellular response of condylar chondrocytes to HCFs. The pattern of HCFs could also be modulated, such as cyclic pattern or with different treatment durations. Further, more specific inhibitors could be adopted to illustrate the influences of FAK, ERK, and PI3K.

\section{Materials and Methods}

\subsection{Isolation and Culture of Primary Mandibular Condylar Chondrocytes}

Mandibular condylar chondrocytes were harvested and cultured as previously reported [58]. Briefly, mandibular condylar cartilage was isolated from Sprague-Dawley (SD) neonatal rats less than three weeks of age and was subsequently minced. After digestion with $0.25 \%$ trypsinase and $0.2 \%$ collagenase, primary condylar chondrocytes were rinsed three times and prepared as a single cell suspension in a growth medium of DMEM (Dulbecco's Modified Eagle's medium) supplemented with 10\% FCS (fetal calf serum), $25 \mathrm{mM}$ HEPES, 1\% L-glutamine, and $100 \mathrm{mg} / \mathrm{mL}$ kanamycin. Cells were seeded and incubated overnight at a high density of $1 \times 10^{6}$ cells $/ \mathrm{cm}^{2}$ in a humidified atmosphere at $37.8^{\circ} \mathrm{C}$ and $5 \% \mathrm{CO}_{2}$. The third-generation condylar chondrocytes were validated by toluidine blue staining a series of immunohistochemistry staining. The cultured chondrocytes were stained with toluidine blue as previously reported [59]. For immunochemistry staining, mandibular condylar chondrocytes were fixed in $4 \%$ formalin solution for $15 \mathrm{~min}$ and permeabilized with $0.3 \%$ Triton X-100 in phosphate-buffered saline (PBS) for $10 \mathrm{~min}$. The fixed cells were then incubated with the primary antibodies, such as anti-type-II collagen (ab34712, Abcam, Cambridge, UK, 1:100), anti-aggrecan (ab36861, Abcam, UK, 1:100), anti-type-X collagen (ab58632, Abcam, UK, 1:500), and anti-type-I collagen (ab34710, Abcam, UK, 1:500) antibodies. The Vectastain Elite ABC Peroxidase kit (Vector Laboratories, Inc., Burlingame, CA, USA) was used for secondary antibody detection. Visualization was done by using DAB as a substrate (ab64238, Abcam, UK). The images were acquired by light microscopy. 


\subsection{Application of Hydrostatic Compressive Forces and Integrin Inhibitor}

The HCF loading system was designed and used as we previously reported [60]. HCFs were applied to monolayer of condylar chondrocytes by an in-house designed computer-controlled pressure chamber (Figure 8). The apparatus was manufactured by SASPG Medical Equipment Factory (Chengdu, China). The apparatus used in this study was designed according to description of Smith and Yamamoto et al. [61,62] with a minor modification. This apparatus enabled the administration of HCFs of $0-250 \mathrm{kPa}$ with a temperature control at $37^{\circ} \mathrm{C}$ under sterile condition. The gas phase of the chamber was maintained at a pressure of scheduled magnitude by continuously infusing a compressed mixed gas $\left(\mathrm{O}_{2}: \mathrm{N}_{2}: \mathrm{CO}_{2}=7.0 \%: 91.3 \%: 1.7 \%\right)$ [63]. Our preliminary experiments have confirmed that the $\mathrm{pH}$ of the DMEM was constant at 7.4 and the temperature was maintained at $37^{\circ} \mathrm{C}$ before and after the experiment [60]. Cells that were seeded in tissue culture dish and placed in the same apparatus under the same conditions were used as controls $(0 \mathrm{kPa})$. All specimens were harvested after the HCFs treatment for $2 \mathrm{~h}$. Chondrocytes $\left(1 \times 10^{6}\right.$ cells $\left./ \mathrm{mL}, 0.2 \mathrm{~mL}\right)$ were grown in 96-well plates and incubated for $2 \mathrm{~h}$ with HCFs of different magnitudes (0, 50, 100, 150, 200, and $250 \mathrm{kPa})$. To block the integrin-dependent signaling, 1 or $5 \mu \mathrm{g} / \mathrm{mL}$ cilengitide, a specific integrin inhibitor [64], was applied $24 \mathrm{~h}$ before the application of $250 \mathrm{kPa} \mathrm{HCF}$.

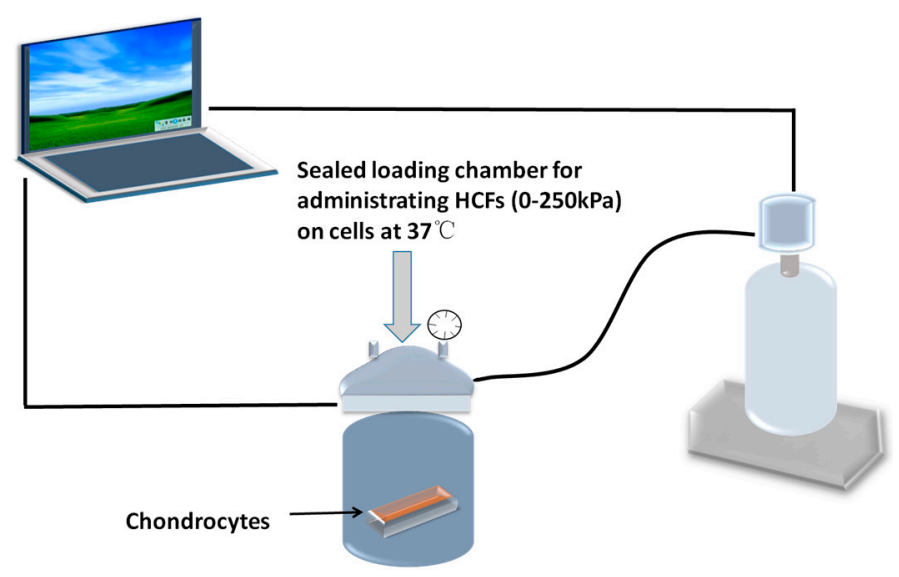

Figure 8. Schematic graph depicting the apparatus for administrating HCFs on mandibular condylar chondrocytes.

\subsection{Cell Viability Assay}

The viability of the cells after HCF treatment was determined over a seven-day period using CCK-8 solution according to the manufacturer's instructions [63]. Cell were added to $10 \mu \mathrm{L}$ of CCK-8 solution in each well of five 96-well plates $(n=5)$ and incubated for $4 \mathrm{~h}$ at $37^{\circ} \mathrm{C}$. The absorbance of each well was determined at $450 \mathrm{~nm}$ using a microplate [65].

\subsection{Detection of Cell Apoptosis}

Mandibular condylar chondrocytes were incubated on uncoated dishes with and without cilengitide ( 1 and $5 \mu \mathrm{g} / \mathrm{mL}$ ) for $24 \mathrm{~h}$ at $37^{\circ} \mathrm{C}$. Cells were double-stained by using an Annexin V-FITC apoptosis detection kit (ab14085, Abcam, Cambridge, UK). Annexin staining was performed according to the manufacturer's instructions. In brief, condylar chondrocytes were collected by centrifugation, re-suspended cells in $500 \mu \mathrm{L}$ of $1 \times$ Binding Buffer and incubated with $5 \mu \mathrm{L}$ of annexin V-FITC and $5 \mu \mathrm{L}$ of propidium iodide (PI $50 \mu \mathrm{g} / \mathrm{mL}$, optional) for $5 \mathrm{~min}$ in the dark at a room temperature. Mandibular condylar chondrocytes were quantitatively analyzed at $488 \mathrm{~nm}$ emission and $530 \mathrm{~nm}$ excitation by Flow Cytometry (BD FACScalibu; BD Biosciences, San Jose, CA, USA). FACS (rluorescence-activated cell sorting) analyses were performed as described previously [66]. Apoptosis was assessed after the staining with FITC-labeled Annexin-V and PI (BD Pharmingen, San Jose, CA, USA). Positive staining 
with FITC-labeled Annexin-V reflects a shift of phosphatidylserine from the inner to the outer layer of the cytoplasmatic membrane, which occurs early in apoptosis. Annexin-V-positive and PI-negative cells were scored as early apoptotic cells. Cells labeled by Annexin V and PI have been determined as late apoptotic. Annexin-negative and PI-positive events display necrotic cells.

\subsection{Actin Staining and Estimation of Cell Surface Area}

Condylar chondrocytes seeded on slide glass with density of $1 \times 10^{6}$ cells $/ \mathrm{cm}^{2}$ were treated with different HCFs according to the protocol mentioned above. Cells were rinsed in PBS, fixed in $4 \%$ paraformaldehyde in neutralized PBS for $30 \mathrm{~min}$, permeabilized with $0.5 \%$ Triton X-100 (Sigma, St. Louis, MO, USA), blocked with 6\% fetal bovine serum (Shanghai Sangon Biological Engineering Technology \& Services Co., Shanghai, China), and incubated with $2 \mathrm{U} / \mathrm{mL}$ rhodamine-phalloidin (Sigma) for $40 \mathrm{~min}, 5 \mathrm{mg} / \mathrm{mL}$ propidium iodide (Sigma) for $10 \mathrm{~min}$. Fluorescence was examined with a fluorescent microscope (Olympus CX-RFL-2, Tokyo, Japan). The surface area of each cell was estimated using a point-counting method [67].

\subsection{Quantitative RT-PCR}

Total RNA was extracted using Trizol reagent (Invitrogen, Carlsbad, CA, USA) and was reverse-transcribed to cDNA using a Reverse Transcription System (Promega, Madison, WI, USA). The input cDNA was standardized and then amplified for 45 cycles with SYBR Green Master Mix and gene-specific primers on an ABI Prism 7900HT machine (Applied Biosystems, Foster City, CA, USA); endogenous GAPDH was regarded as an internal control, and samples were analyzed in triplicate. Primers and probes were designed using annotated sequences from the porcine database and Applied Biosystem Primer Express software. The sequences of synthesized primers and probes are shown in Table 1. Each well was loaded with $2.5 \mu \mathrm{L}$ SYBR green master mix, $1.2 \mu \mathrm{L} \mathrm{H}_{2} \mathrm{O}$, and $0.15 \mu \mathrm{L}$ of each primer $(10 \mu \mathrm{M}$; final concentration, $250 \mathrm{nM}) .1 \mu \mathrm{L}$ cDNA was amplified using a standardized program with a 10 min denaturing step following 45 cycles of $5 \mathrm{~s} 95^{\circ} \mathrm{C}, 15 \mathrm{~s} 65^{\circ} \mathrm{C}$, and $15 \mathrm{~s}$ at $72{ }^{\circ} \mathrm{C}$, melting point analysis in $0.1{ }^{\circ} \mathrm{C}$ steps, and a final cooling step. Relative quantification of target gene expression was calculated according to SDS2.4 RQ manager (Applied Biosystems, Foster City, CA, USA). The PCR efficiencies for target gene (amplicons) were calculated using the Relative Quantification Software from ABI Molecular Biochemicals (Applied Biosystems, Foster City, CA, USA). Target gene mRNA was normalized according to the relative content of the target gene under each treatment condition. Results were shown as fold inductions of target gene mRNA compared with the untreated control.

Table 1. Primer sequences for real-time quantitative polymerase chain reaction analysis of the mRNA expression of Itga2, Itga5, Itgb1, FAK, ERK1, ERK2, PI3K1, and GAPDH genes.

\begin{tabular}{|c|c|c|}
\hline Gene & Accession No. & Primers $\left(5^{\prime}-3^{\prime}\right)(F=$ Forward; $R=$ Reverse $)$ \\
\hline Itga2 & XM_001075558.5 & $\begin{array}{l}\text { F: TGGAATTTGTTCTGATGTCAGTCC } \\
\text { R: GTGGTCAAGTTAAAGACAACTCTT }\end{array}$ \\
\hline Itga5 & NM_001314041.1 & $\begin{array}{l}\text { F: TGCAGCACCATTCAATTTGACAGC } \\
\text { R: TCATTCTGTGGGTCCTTTTCTGTG }\end{array}$ \\
\hline Itgb1 & XM_006255824.1 & $\begin{array}{l}\text { F: AATTCAAGAGGGCTGAAGACTAC } \\
\text { R: TGTCAGTAAGACTAAGCACG }\end{array}$ \\
\hline FAK & XM_006520433.2 & $\begin{array}{l}\text { F: CCAAGTTCGAGTACTAAGACTCACC } \\
\text { R: AAATCCATAGCAGGCCACGTGC }\end{array}$ \\
\hline ERK1 & NM_017347.2 & $\begin{array}{l}\text { F: AGAGATCATGCTTAACTCCAAG } \\
\text { R: TTCATGTTAATGATACAATTTAGGTCCTC }\end{array}$ \\
\hline ERK2 & XM_006522147.3 & $\begin{array}{l}\text { F: CTGCACCGTGACCTCAAGCC } \\
\text { R: CAATGGACTTGGTATAACCCTTGG }\end{array}$ \\
\hline PI3K1 & XM_006240005.2 & $\begin{array}{l}\text { F: CTGATTGGCTACGACGTCAC } \\
\text { R: GAAGAAGCTCTGAAGGATGGTGTC }\end{array}$ \\
\hline GAPDH & XM_017321385.1 & $\begin{array}{l}\text { F: AAAGGCATCTTGGGCTACACCG } \\
\text { R: ATGAGGTCCACCACCCTGTTG }\end{array}$ \\
\hline
\end{tabular}




\subsection{Western Blot Analysis}

Total cellular proteins were extracted using Mammalian protein extraction reagent (Sigma-Aldrich, St. Louis, MO, USA) with $1 \times$ Roche cocktail protease inhibitor mixture. The lysates were collected, centrifuged at 12,000 rpm using a microcentrifuge (Eppendorf, Germany) for $10 \mathrm{~min}$ at $4{ }^{\circ} \mathrm{C}$, pellets were discarded, and supernatants were transferred to a new Eppendorf tube. Protein was quantified using the BCA protein assay kit (Pierce BCA protein assay kit, Thermo Fisher scientific, Waltham, MA, USA). Samples were boiled in an equal volume of SDS loading buffer for $10 \mathrm{~min}$ and separated on $10 \%$ to $12 \%$ SDS-PAGE gels. Proteins resolved on the gels were transferred to $0.22 \mu \mathrm{m}$ polyvinylidenedifluoride (PVDF) membranes (Millipore, Billerica, MA, USA) for $2 \mathrm{~h}$ at $90 \mathrm{~V}$, according to standard procedures. The bolts were incubated and nonspecific binding sites were blocked with $5 \%$ BSA/TBS-Tween 20 followed by incubation in primary antibodies at $4{ }^{\circ} \mathrm{C}$ overnight and then washed three times in the $1 \times$ TBS-Tween 20 buffer. Horseradish Peroxidase (HRP)-conjugated anti-mouse or anti-rabbit secondary antibodies were used at 1:750 (Santa Cruz Biotechnology, Santa Cruz, CA, USA). Detection was performed using Super Signal West Femto Chemiluminscence Substrate (Thermo Fisher scientific, Waltham, MA, USA). The blots were visualized using an Image Quant LAS4000 biomolecular imager (GE Healthcare, Bethesda, MD, USA). Proteins were normalized to the level of $\beta$-actin protein.

\subsection{Statistical Analysis}

Data were expressed as mean \pm standard deviation (SD). Statistical analysis was performed using unpaired $t$-test or one-way analysis of variance depending on whether the data were normally distributed. All statistical analysis was done in SPSS version 20.0 (IBM, Armonk, NY, USA), $p<0.05$ was considered to be statistically significant.

Acknowledgments: This study was supported by the funds of National Natural Science Foundation of China (Grant No. 81400475, No. 81470724 and No. 81500813) and Zhejiang Provincial Natural Science Foundation of China (No. LY14H140006, No. LY14H140002, and No. LY17H140010).

Author Contributions: Dandan Ma, Haiping Lu, and Gang Wu did experimental design; Jing Jin, Dandan Ma, Taotao Xu, Liquan Deng, Lusi Fu, Xiaoxing Kou, Mengjie Wu and Yi Liu performed the experiments and collected the data; Dandan Ma and Gang Wu did the data interpretation; Dandan Ma and Gang Wu wrote the manuscript; Dandan Ma, Haiping Lu, and Gang Wu gave the final approval.

Conflicts of Interest: The authors declare no conflict of interests.

\section{References}

1. Chai, Y.; Maxson, R.E., Jr. Recent advances in craniofacial morphogenesis. Dev. Dyn. 2006, 235, $2353-2375$. [CrossRef]

2. Hinton, R.J. Effect of condylotomy on matrix synthesis and mineralization in the rat mandibular condylar cartilage. Arch. Oral Biol. 1989, 34, 1003-1009. [CrossRef]

3. Kantomaa, T.; Pirttiniemi, P.; Tuominen, M.; Poikela, A. Glycosaminoglycan synthesis in the mandibular condyle during growth adaptation. Acta Anat. 1994, 151, 88-96. [CrossRef]

4. Kiliaridis, S.; Thilander, B.; Kjellberg, H.; Topouzelis, N.; Zafiriadis, A. Effect of low masticatory function on condylar growth: A morphometric study in the rat. Am. J. Orthod. Dentofac. Orthop. 1999, 116, 121-125. [CrossRef]

5. Bouvier, M. Variation in alkaline-phosphatase activity with changing load on the mandibular condylar cartilage in the rat. Arch. Oral Biol. 1987, 32, 671-675. [CrossRef]

6. Hinton, R.J.; Carlson, D.S. Response of the mandibular joint to loss of incisal function in the rat. Acta Anat. 1986, 125, 145-151. [CrossRef]

7. Pirttiniemi, P.; Kantomaa, T.; Salo, L.; Tuominen, M. Effect of reduced articular function on deposition of type I and type II collagens in the mandibular condylar cartilage of the rat. Arch. Oral Biol. 1996, 41, 127-131. [CrossRef]

8. Habib, H.; Hatta, T.; Udagawa, J.; Zhang, L.; Yoshimura, Y.; Otani, H. Fetal jaw movement affects condylar cartilage development. J. Dent. Res. 2005, 84, 474-479. [CrossRef] 
9. Pirttiniemi, P.; Kantomaa, T.; Sorsa, T. Effect of decreased loading on the metabolic activity of the mandibular condylar cartilage in the rat. Eur. J. Orthod. 2004, 26, 1-5. [CrossRef]

10. Kim, J.Y.; Kim, S.T.; Cho, S.W.; Jung, H.S.; Park, K.T.; Son, H.K. Growth effects of botulinum toxin type A injected into masseter muscle on a developing rat mandible. Oral Dis. 2008, 14, 626-632. [CrossRef]

11. Jung, J.K.; Sohn, W.J.; Lee, Y.; Bae, Y.C.; Choi, J.K.; Kim, J.Y. Morphological and cellular examinations of experimentally induced malocclusion in mice mandibular condyle. Cell Tissue Res. 2014, 355, 355-363. [CrossRef]

12. Humphries, M.J. Integrin structure. Biochem. Soc. Trans. 2000, 28, 311-339. [CrossRef]

13. Woods, V.L., Jr.; Schreck, P.J.; Gesink, D.S.; Pacheco, H.O.; Amiel, D.; Akeson, W.H.; Lotz, M. Integrin expression by human articular chondrocytes. Arthritis Rheum. 1994, 37, 537-544. [CrossRef]

14. Wright, M.O.; Nishida, K.; Bavington, C.; Godolphin, J.L.; Dunne, E.; Walmsley, S.; Jobanputra, P.; Nuki, G.; Salter, D.M. Hyperpolarisation of cultured human chondrocytes following cyclical pressure-induced strain: Evidence of a role for $\alpha 5 \beta 1$ integrin as a chondrocyte mechanoreceptor. J. Orthop. Res. 1997, 15, 742-747. [CrossRef]

15. Luo, D.Y.; Wazir, R.; Tian, Y.; Yue, X.; Wei, T.Q.; Wang, K.J. Integrin $\alpha$ v mediates contractility whereas integrin $\alpha 4$ regulates proliferation of human bladder smooth muscle cells via FAK pathway under physiological stretch. J. Urol. 2013, 190, 1421-1429. [CrossRef]

16. Ju, L.; Zhou, C. Association of integrin $\beta 1$ and c-MET in mediating EGFR TKI gefitinib resistance in non-small cell lung cancer. Cancer Cell Int. 2013, 13, 15. [CrossRef]

17. Luu, N.T.; Glen, K.E.; Egginton, S.; Rainger, G.E.; Nash, G.B. Integrin-substrate interactions underlying shear-induced inhibition of the inflammatory response of endothelial cells. Thromb. Haemost. 2013, 109, 298-308. [CrossRef]

18. Liu, C.; Kaneko, S.; Soma, K. Expression of integrin $\alpha 5 \beta 1$, focal adhesion kinase and integrin-linked kinase in rat condylar cartilage during mandibular lateral displacement. Arch. Oral Biol. 2008, 53, 701-708. [CrossRef]

19. Hirsch, M.S.; Lunsford, L.E.; Trinkaus-Randall, V.; Svoboda, K.K. Chondrocyte survival and differentiation in situ are integrin mediated. Dev. Dyn. 1997, 210, 249-263. [CrossRef]

20. Hehlgans, S.; Haase, M.; Cordes, N. Signalling via integrins: Implications for cell survival and anticancer strategies. Biochim. Biophys. Acta 2007, 1775, 163-180. [CrossRef]

21. Diercke, K.; Kohl, A.; Lux, C.J.; Erber, R. Strain-dependent up-regulation of ephrin-B2 protein in periodontal ligament fibroblasts contributes to osteogenesis during tooth movement. J. Biol. Chem. 2011, 286, 37651-37664. [CrossRef]

22. Hong, S.Y.; Jeon, Y.M.; Lee, H.J.; Kim, J.G.; Baek, J.A.; Lee, J.C. Activation of rhoa and FAK induces ERK-mediated osteopontin expression in mechanical force-subjected periodontal ligament fibroblasts. Mol. Cell. Biochem. 2010, 335, 263-272. [CrossRef]

23. Ory, S.; Morrison, D.K. Signal transduction: Implications for Ras-dependent ERK signaling. Curr. Biol. 2004, 14, R277-R278. [CrossRef]

24. Sonoda, Y.; Matsumoto, Y.; Funakoshi, M.; Yamamoto, D.; Hanks, S.K.; Kasahara, T. Anti-apoptotic role of focal adhesion kinase (FAK). Induction of inhibitor-of-apoptosis proteins and apoptosis suppression by the overexpression of FAK in a human leukemic cell line, HL-60. J. Biol. Chem. 2000, 275, 16309-16315. [CrossRef]

25. Nishio, C.; Tanimoto, K.; Hirose, M.; Horiuchi, S.; Kuroda, S.; Tanne, K.; Tanaka, E. Stress analysis in the mandibular condyle during prolonged clenching: A theoretical approach with the finite element method. Proc. Inst. Mech. Eng. H 2009, 223, 739-748. [CrossRef]

26. Abe, S.; Kawano, F.; Kohge, K.; Kawaoka, T.; Ueda, K.; Hattori-Hara, E.; Mori, H.; Kuroda, S.; Tanaka, E. Stress analysis in human temporomandibular joint affected by anterior disc displacement during prolonged clenching. J. Oral Rehabil. 2013, 40, 239-246. [CrossRef]

27. Liang, W.; Ren, K.; Liu, F.; Cui, W.; Wang, Q.; Chen, Z.; Fan, W. Periodic mechanical stress stimulates the FAK mitogenic signal in rat chondrocytes through ERK1/2 activity. Cell. Physiol. Biochem. 2013, 32, 915-930. [CrossRef]

28. Lucchinetti, E.; Adams, C.S.; Horton, W.E., Jr.; Torzilli, P.A. Cartilage viability after repetitive loading: A preliminary report. Osteoarthr. Cartil. 2002, 10, 71-81. [CrossRef]

29. Chen, C.T.; Bhargava, M.; Lin, P.M.; Torzilli, P.A. Time, stress, and location dependent chondrocyte death and collagen damage in cyclically loaded articular cartilage. J. Orthop. Res. 2003, 21, 888-898. [CrossRef] 
30. Tatsumura, M.; Sakane, M.; Ochiai, N.; Mizuno, S. Off-loading of cyclic hydrostatic pressure promotes production of extracellular matrix by chondrocytes. Cells Tissues Org. 2013, 198, 405-413. [CrossRef]

31. Fioravanti, A.; Cantarini, L.; Chellini, F.; Manca, D.; Paccagnini, E.; Marcolongo, R.; Collodel, G. Effect of hyaluronic acid (MW 500-730 kDa) on proteoglycan and nitric oxide production in human osteoarthritic chondrocyte cultures exposed to hydrostatic pressure. Osteoarthr. Cartil. 2005, 13, 688-696. [CrossRef]

32. Pascarelli, N.A.; Collodel, G.; Moretti, E.; Cheleschi, S.; Fioravanti, A. Changes in ultrastructure and cytoskeletal aspects of human normal and osteoarthritic chondrocytes exposed to interleukin-1 $\beta$ and cyclical hydrostatic pressure. Int. J. Mol. Sci. 2015, 16, 26019-26034. [CrossRef]

33. Huang, L.; Li, M.; Li, H.; Yang, C.; Cai, X. Study of differential properties of fibrochondrocytes and hyaline chondrocytes in growing rabbits. Br. J. Oral Maxillofac. Surg. 2015, 53, 187-193. [CrossRef]

34. Takano-Yamamoto, T.; Soma, S.; Nakagawa, K.; Kobayashi, Y.; Kawakami, M.; Sakuda, M. Comparison of the effects of hydrostatic compressive force on glycosaminoglycan synthesis and proliferation in rabbit chondrocytes from mandibular condylar cartilage, nasal septum, and spheno-occipital synchondrosis in vitro. Am. J. Orthod. Dentofac. Orthop. 1991, 99, 448-455. [CrossRef]

35. Cao, L.; Lee, V.; Adams, M.E.; Kiani, C.; Zhang, Y.; Hu, W.; Yang, B.B. $\beta_{1}$-Integrin-collagen interaction reduces chondrocyte apoptosis. Matrix Biol. 1999, 18, 343-355. [CrossRef]

36. Ren, K.; Liu, F.; Huang, Y.; Liang, W.; Cui, W.; Wang, Q.; Fan, W. Periodic mechanical stress activates integrin $\beta 1$-dependent Src-dependent PLC $\gamma 1$-independent Rac1 mitogenic signal in rat chondrocytes through ERK1/2. Cell. Physiol. Biochem. 2012, 30, 827-842. [CrossRef]

37. Ross, R.S. The extracellular connections: The role of integrins in myocardial remodeling. J. Card. Fail. 2002, 8, S326-S331. [CrossRef]

38. McGill, G.; Shimamura, A.; Bates, R.C.; Savage, R.E.; Fisher, D.E. Loss of matrix adhesion triggers rapid transformation-selective apoptosis in fibroblasts. J. Cell Biol. 1997, 138, 901-911. [CrossRef]

39. Wen, H.; Blume, P.A.; Sumpio, B.E. Role of integrins and focal adhesion kinase in the orientation of dermal fibroblasts exposed to cyclic strain. Int. Wound J. 2009, 6, 149-158. [CrossRef]

40. Lal, H.; Verma, S.K.; Smith, M.; Guleria, R.S.; Lu, G.; Foster, D.M.; Dostal, D.E. Stretch-induced MAP kinase activation in cardiac myocytes: Differential regulation through $\beta 1$-integrin and focal adhesion kinase. J. Mol. Cell. Cardiol. 2007, 43, 137-147. [CrossRef]

41. Frisch, S.M.; Vuori, K.; Ruoslahti, E.; Chan-Hui, P.Y. Control of adhesion-dependent cell survival by focal adhesion kinase. J. Cell Biol. 1996, 134, 793-799. [CrossRef]

42. Hungerford, J.E.; Compton, M.T.; Matter, M.L.; Hoffstrom, B.G.; Otey, C.A. Inhibition of pp125FAK in cultured fibroblasts results in apoptosis. J. Cell Biol. 1996, 135, 1383-1390. [CrossRef]

43. Liao, C.H.; Sang, S.; Ho, C.T.; Lin, J.K. Garcinol modulates tyrosine phosphorylation of FAK and subsequently induces apoptosis through down-regulation of Src, ERK, and AKT survival signaling in human colon cancer cells. J. Cell. Biochem. 2005, 96, 155-169. [CrossRef]

44. Schlaepfer, D.D.; Hanks, S.K.; Hunter, T.; van der Geer, P. Integrin-mediated signal transduction linked to Ras pathway by GRB2 binding to focal adhesion kinase. Nature 1994, 372, 786-791. [CrossRef]

45. Mobasheri, A.; Carter, S.D.; Martin-Vasallo, P.; Shakibaei, M. Integrins and stretch activated ion channels; putative components of functional cell surface mechanoreceptors in articular chondrocytes. Cell Biol. Int. 2002, 26, 1-18. [CrossRef]

46. Shakibaei, M.; Schulze-Tanzil, G.; de Souza, P.; John, T.; Rahmanzadeh, M.; Rahmanzadeh, R.; Merker, H.J. Inhibition of mitogen-activated protein kinase kinase induces apoptosis of human chondrocytes. J. Biol. Chem. 2001, 276, 13289-13294. [CrossRef]

47. Kiyokawa, E.; Hashimoto, Y.; Kurata, T.; Sugimura, H.; Matsuda, M. Evidence that DOCK180 up-regulates signals from the CrkII-p130(Cas) complex. J. Biol. Chem. 1998, 273, 24479-24484. [CrossRef]

48. Chen, H.C.; Guan, J.L. Association of focal adhesion kinase with its potential substrate phosphatidylinositol 3-kinase. Proc. Natl. Acad. Sci. USA 1994, 91, 10148-10152. [CrossRef]

49. Buckley, C.D.; Pilling, D.; Henriquez, N.V.; Parsonage, G.; Threlfall, K.; Scheel-Toellner, D.; Simmons, D.L.; Akbar, A.N.; Lord, J.M.; Salmon, M. RGD peptides induce apoptosis by direct caspase-3 activation. Nature 1999, 397, 534-539.

50. Folkman, J.; Moscona, A. Role of cell shape in growth control. Nature 1978, 273, 345-349. [CrossRef]

51. Gospodarowicz, D.; Greenburg, G.; Birdwell, C.R. Determination of cellular shape by the extracellular matrix and its correlation with the control of cellular growth. Cancer Res. 1978, 38, 4155-4171. 
52. Engel, F.E.; Khare, A.G.; Boyan, B.D. Phenotypic changes of rabbit mandibular condylar cartilage cells in culture. J. Dent. Res. 1990, 69, 1753-1758. [CrossRef]

53. Adams, S.L.; Pallante, K.M.; Pacifici, M. Effects of cell shape on type $x$ collagen gene expression in hypertrophic chondrocytes. Connect. Tissue Res. 1989, 20, 223-232. [CrossRef]

54. Gerstenfeld, L.C.; Kelly, C.M.; von Deck, M.; Lian, J.B. Comparative morphological and biochemical analysis of hypertrophic, non-hypertrophic and $\mathrm{L}, 25(\mathrm{OH})_{2} \mathrm{~d}_{3}$ treated non-hypertrophic chondrocytes. Connect. Tissue Res. 1990, 24, 29-39. [CrossRef]

55. Bonassar, L.J.; Grodzinsky, A.J.; Srinivasan, A.; Davila, S.G.; Trippel, S.B. Mechanical and physicochemical regulation of the action of insulin-like growth factor-I on articular cartilage. Arch. Biochem. Biophys. 2000, 379, 57-63. [CrossRef]

56. Grodzinsky, A.J.; Levenston, M.E.; Jin, M.; Frank, E.H. Cartilage tissue remodeling in response to mechanical forces. Annu. Rev. Biomed. Eng. 2000, 2, 691-713. [CrossRef]

57. Sanz-Ramos, P.; Mora, G.; Ripalda, P.; Vicente-Pascual, M.; Izal-Azcarate, I. Identification of signalling pathways triggered by changes in the mechanical environment in rat chondrocytes. Osteoarthr. Cartil. 2012, 20, 931-939. [CrossRef]

58. Seguin, C.A.; Bernier, S.M. TNF $\alpha$ suppresses link protein and type II collagen expression in chondrocytes: Role of MEK1/2 and NF-кB signaling pathways. J. Cell. Physiol. 2003, 197, 356-369. [CrossRef]

59. Takigawa, M.; Takano, T.; Suzuki, F. Restoration by cyclic AMP of the differentiated phenotype of chondrocytes from de-differentiated cells pretreated with retinoids. Mol. Cell. Biochem. 1982, 42, 145-153. [CrossRef]

60. Wu, M.J.; Gu, Z.Y.; Sun, W. Effects of hydrostatic pressure on cytoskeleton and BMP-2, TGF-B, SOX-9 production in rat temporomandibular synovial fibroblasts. Osteoarthr. Cartil. 2008, 16, 41-47. [CrossRef]

61. Yamamoto, T.; Kita, M.; Kimura, I.; Oseko, F.; Terauchi, R.; Takahashi, K.; Kubo, T.; Kanamura, N. Mechanical stress induces expression of cytokines in human periodontal ligament cells. Oral Dis. 2006, 12, 171-175. [CrossRef]

62. Smith, R.L.; Rusk, S.F.; Ellison, B.E.; Wessells, P.; Tsuchiya, K.; Carter, D.R.; Caler, W.E.; Sandell, L.J.; Schurman, D.J. In vitro stimulation of articular chondrocyte mrna and extracellular matrix synthesis by hydrostatic pressure. J. Orthop. Res. 1996, 14, 53-60. [CrossRef]

63. Ozawa, H.; Imamura, K.; Abe, E.; Takahashi, N.; Hiraide, T.; Shibasaki, Y.; Fukuhara, T.; Suda, T. Effect of a continuously applied compressive pressure on mouse osteoblast-like cells (MC3T3-E1) in vitro. J. Cell. Physiol. 1990, 142, 177-185. [CrossRef]

64. Oliveira-Ferrer, L.; Hauschild, J.; Fiedler, W.; Bokemeyer, C.; Nippgen, J.; Celik, I.; Schuch, G. Cilengitide induces cellular detachment and apoptosis in endothelial and glioma cells mediated by inhibition of FAK/Src/AKT pathway. J. Exp. Clin. Cancer Res. 2008, 27, 86. [CrossRef]

65. Bae, J.Y.; Han, D.W.; Wakitani, S.; Nawata, M.; Hyon, S.H. Biological and biomechanical evaluations of osteochondral allografts preserved in cold storage solution containing epigallocatechin gallate. Cell Transplant. 2010, 19, 681-689. [CrossRef]

66. Mayr, M.; Li, C.; Zou, Y.; Huemer, U.; Hu, Y.; Xu, Q. Biomechanical stress-induced apoptosis in vein grafts involves p38 mitogen-activated protein kinases. FASEB J. 2000, 14, 261-270.

67. Cruz-Orive, L.M.; Weibel, E.R. Recent stereological methods for cell biology: A brief survey. Am. J. Physiol. 1990, 258, L148-L156.

(C) 2016 by the authors; licensee MDPI, Basel, Switzerland. This article is an open access article distributed under the terms and conditions of the Creative Commons Attribution (CC-BY) license (http:/ / creativecommons.org/licenses/by/4.0/). 